\title{
Long-term follow-up after attempted angioplasty of saphenous vein grafts: the Thoraxcenter experience 1981-1988
}

\author{
B. J. Meester*, M. Samson $\dagger$, H. Suryapranata*, G. Bonsel $\ddagger$, M. van den Brand*, P. J. de Feyter*and \\ P. W. SerRuYs* \\ * Thoraxcenter and + Institute for Medical Technology Assessment, Erasmus University, Rotterdam, The Netherlands
}

KEY WORDS: Bypass surgery, angioplasty of saphenous vein grafts, long-term follow-up.

Between 1981 and 1988, 107 percutaneous transluminal coronary angioplasty (PTCA) procedures, including repeat PTCA, were performed in 84 patients with previous coronary artery bypass grafting (CABG). Fifty-nine patients underwent a first angioplasty of the vein graft alone, and 25 underwent a first PTCA of the graft and one or more native vessels. Seventeen patients underwent two procedures, four patients three procedures and one patient four procedures. In 84 first angioplasties, 133 lesions were attempted; 40 lesions in native vessels and 93 graft lesions (28 ostial stenoses, 33 shaft stenoses, and 32 stenoses at the distal anastomosis).

Three patients died during their hospital stay. Two patients underwent emergency CABG. Seven patients sustained an acute myocardial infarction (AMI), among whom five underwent a PTCA of an occluded vessel. The clinical primary success rate per patient was $82 \%$. After five years, $70 \%$ of patients were alive. At a median follow-up of $2 \cdot 1$ years, $41 \%$ of patients were alive and event-free (no AMI, no repeat $C A B G$, no repeat $P T C A$ ). Symptomatic improvement was maintained in $36 \%$ of patients. Angioplasty of grafts may be an alternative to re-operation in selected patients with previous bypass surgery.

\section{Introduction}

Coronary artery bypass grafting (CABG) has developed into a safe and effective procedure for relieving refractory angina, and improves prognosis in selected patients with left main or multivessel coronary artery disease. However, recurrent symptoms of myocardial ischaemia often develop after bypass surgery, requiring either reinstitution of medical therapy or repeat bypass surgery.

Repeat direct myocardial revascularization is technically more difficult and is generally associated with a higher morbidity and mortality than the initial surgery ${ }^{(1-6)}$. Although percutaneous transluminal coronary angioplasty (PTCA) is an attractive alternative to re-operation in patients with prior bypass surgery, the long-term results of this procedure have only been published over the last two or three years ${ }^{77.81}$. This report describes our experience with the use of angioplasty in the treatment of partially or totally occluded saphenous vein bypass grafts.

\section{Methods}

\section{STUDY PATIENTS}

Between February 1981 and October 1988, 2620 consecutive PTCA procedures were performed at the Thoraxcenter in Rotterdam. All 84 consecutive patients with previous bypass surgery who underwent a first PTCA of the saphenous vein bypass graft alone (59

Submitted for publication on 25 April 1990 , and in revised form 30 July 1990.

tM. Samson is a research fellow from the Department of Cardiology. Quebec Heart Institute. Laval University, Quebec, Canada.

Correspondence: Prof. P. W. Serruys, MD. PhD, Catheterization Laboratory, Thoraxcenter. Erasmus University, P.O. Box 1738, 3000 DR Rotterdam. The Netherlands. patients), or a first PTCA of the graft and one or more native vessels ( 25 patients), were retrospectively reviewed and provide the basis for this study. In these 84 patients $107(4 \cdot 1 \%)$ bypass graft angioplasty procedures, including repeat angioplasties, were performed. Fifteen (18\%) patients underwent a dilatation of an occluded saphenous vein graft.

Fifty-six patients $(67 \%)$ received an aortocoronary circular sequential saphenous vein graft. A proximal occlusion was located between the connection of the aorta and the first anastomosis, a mid-occlusion after the first anastomosis and before the most distal anastomosis, and a distal occlusion in the distal part of the graft. Seven of the 56 patients also had a single graft. Single grafts alone were placed in 26 patients. Two patients had received a snakegraft. The mean interval between coronary bypass surgery and coronary angioplasty was 4.7 years (range 1 month to 13.5 years). Eight patients $(10 \%)$ had coronary angioplasty within 6 months and $18(21 \%)$ within one year of coronary bypass surgery. Thirty-nine patients $(46 \%)$ had a PTCA more than 5 years after CABG (Fig. 1). Two patients had had two previous bypass procedures.

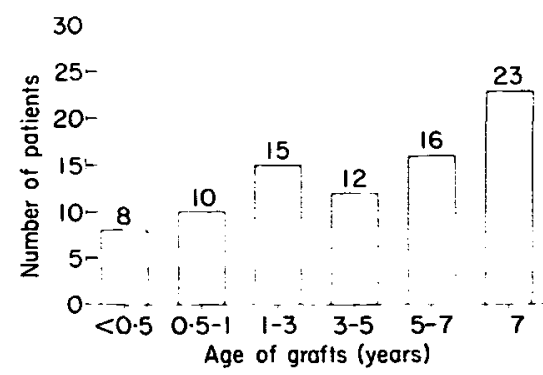

Figure 1 Time interval between PTCA and previous surgery. 
In 84 primary angioplasties, 133 lesions were attempted. There were 93 lesions in the saphenous vein bypass grafts, and 40 lesions in native vessels. The 93 bypass graft stenoses consisted of $28(30 \%)$ proximal stenoses, $33(36 \%)$ stenoses in the shaft of the graft, and 32 $(34 \%)$ at the distal end to side anastomosis. Twenty-five patients underwent a PTCA of the graft and one or more native vessels; the number of attempted native vessel stenoses ranged from one to three per patient (mean: 1.9). Angiographic success was defined as a reduction in the severity of all attempted lesions to less than $50 \%$ luminal diameter narrowing. Clinical success was defined when angiographic success was achieved with the abolition of acute ischaemic symptoms and without progression to myocardial infarction, emergency surgery or death.

All patients had stable or unstable angina pectoris despite intensive pharmacological therapy, and were considered to be appropriate candidates for repeat bypass surgery. Sixty-five $(77 \%)$ of the patients were men. The mean age was 60 years, ranging from 39 to 79 years. Before angioplasty, the New York Heart Association classification was class 2 in $14(17 \%)$, class 3 in $31(37 \%)$, and class 4 in $39(46 \%)$. Twenty patients $(24 \%)$ had hypertension (blood pressure higher than $140 / 90 \mathrm{mmHg}$ ), 10 patients $(12 \%)$ had diabetes mellitus requiring medication, $18(21 \%)$ had hypercholesterolaemia (more than $\left.240 \mathrm{mg} . \mathrm{dl}^{-1}\right)$, and $54(64 \%)$ had a history of previous acute myocardial infarction (AMI). Five patients $(6 \%)$ had single-vessel disease, 21 (25\%) two-vessel and 58 $(69 \%)$ triple-vessel disease.

The left ventricular ejection fraction was calculated from contrast ventriculography, as previously described ${ }^{[9]}$. The mean ejection fraction was $0 \cdot 55 \pm 0 \cdot 13$. Eight $(10 \%)$ patients had an ejection fraction of less than $0 \cdot 35$.

\section{CORONARY ANGIOPLASTY}

Management decisions on the individual patients were made after review of the coronary arteriograms and discussion with the cardiothoracic surgeons. Patients were referred for angioplasty if the lesions considered responsible for significant myocardial ischaemia documented by objective noninvasive studies (exercise stress testing or myocardial scintigraphy (when not clinically contraindicated) and by coronary cinearteriography, were thought both by the cardiologist and the cardiac surgeon, to be technically suitable for PTCA.

The patient's coronary anatomy was the primary determinant of whether or not angioplasty would be attempted. However, some patients underwent a PTCA because they were not considered good candidates for bypass surgery. This surgical risk assessment was determined by the presence of multiple prior bypass operations with or without postoperative complications, concomitant severe medical conditions (for example severe diabetes mellitus with marked end-organ damage, renal failure) or severe left ventricular dysfunction (left ventricular ejection fraction $\leqslant 35 \%$ ).

The procedure used in our laboratory has been previously described ${ }^{[10-12]}$. Before the procedure, $250 \mathrm{mg}$ of acetylsalicylic acid and $10000 \mathrm{U}$ of heparine were administered intravenously. All procedures were performed with surgical stand-by. After the procedure, all patients were followed up for $24 \mathrm{~h}$ in the medium care unit, where the ECG and cardiac enzyme levels were monitored. A peri-interventional myocardial infarction was diagnosed if either new pathologic $Q$ waves developed or a cardiac enzyme elevation ( $\geq 2$ times normal value) was documented. Following successful angioplasty, patients were continued on nifedipine, 40 to $60 \mathrm{mg}$ day $^{-1}$, and aspirin, $500 \mathrm{mg} \mathrm{day}{ }^{-1}$, for a period of 6 months after PTCA.

\section{TECHNICAL ASPECTS}

The method of angioplasty changed during the study period: prior to February 1983 a non-steerable catheter system was used; after then, the long guide-wire technique or a monorail system was used. Angioplasty of the lesion considered to be the most important (according to severity and morphology of the lesion, size of vessel or graft, wall motion of area at risk and localization of ischaemic electrocardiographic changes at rest) was attempted first.

All angioplasty procedures were performed by utilizing the femoral (66 patients) or brachial (15 patients) techniques, or both (three patients). Guiding catheter selection was determined by the configuration and orientation of the saphenous vein graft and the diameter of the ascending aorta. The mean maximal inflation pressure was $11 \cdot 0 \pm 2 \cdot 3$ atmospheres (range 5 to 18 ) with a mean maximal inflation time of $189 \pm 147$ seconds (range 10 to 740).

\section{FOLLOW-UP}

Procedural details, including complications, were recorded at the time of the PTCA in our database. Primary end-points considered at follow-up were death, non-fatal myocardial infarction, recurrent angina pectoris necessitating repeat bypass surgery or repeat angioplasty, and symptomatic improvement. Follow-up information was available in $100 \%$ of patients. It was first established for all patients whether they were still alive, by means of a letter to the civil registry. If they were alive, follow-up data were obtained by questionnaires and by telephone $(97.6 \%)$, or by interview during out-patient visits $(2 \cdot 4 \%)$.

\section{STATISTICS}

All data are presented as the mean \pm 1 standard deviation. Life table analysis was performed according to the Kaplan-Meier method. The generalized Willcoxon or Breslow test was utilized to detect differences between the sub-groups. A $P$ value of $<0.05$ was considered statistically significant.

\section{Results}

\section{INITIAL RESULTS}

The angiographic primary success rate per lesion was $88 \%$ for bypass graft stenoses, and $93 \%$ for native vessel stenoses. The angiographic primary success rate was $86 \%$ for proximal lesions, $97 \%$ for shaft lesions, and $81 \%$ for distal lesions (Table 1). The clinical primary success rate 
Table 1 Primary angiographic success at first PTCA (per lesion)

\begin{tabular}{lccc}
\hline & & \multicolumn{2}{c}{ Successful } \\
Lesion site & $(\mathrm{n})$ & $(n)$ & $(\%)$ \\
\cline { 3 - 4 } & & & \\
\hline SVG proximal & 28 & $24 / 28$ & 86 \\
$\quad$ middle & 33 & $32 / 33$ & 97 \\
$\quad$ distal & 32 & $26 / 32$ & 81 \\
Native artery & 40 & $37 / 40$ & 93 \\
Total & 133 & $119 / 133$ & 89 \\
& & & \\
\hline
\end{tabular}

SVG: saphenous vein graft.

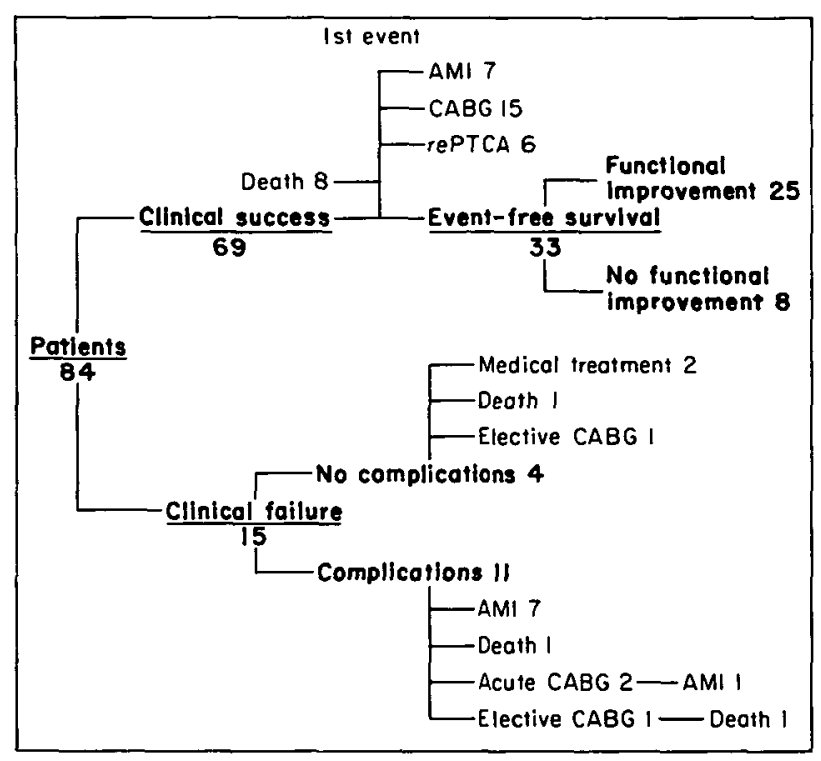

Figure 2 Results of angioplasty of bypass grafts: procedural complications at first angioplasty and long-term follow-up after successful angioplasty. AMI: acute myocardial infarction; CABG: coronary artery bypass grafting; rePTCA: repeat percutaneous transluminal coronary angioplasty.

per patient was $82 \%$; 69 of the 84 primary procedures were successful and without complications. The clinical primary success rate was $72 \%$ for patients who underwent a PTCA of the graft and one or more native vessels and $86 \%$ for patients who underwent a PTCA of the bypass graft alone. After February 1983, when the PTCA procedures were carried out with the long guide-wire technique or a monorail system, a higher clinical primary success rate was found $(85 \%$ versus $67 \%$ ). However, only $14 \%$ of the procedures were performed before February 1983.

Thirteen complications occurred in 11 patients (Fig. 2). There was one procedure-related death, and two patients died during their hospital stay. Of these two patients one died of an acute myocardial infarction 3 days after the PTCA attempt had failed, and the other died of renal failure 10 days after an elective repeat CABG. Two

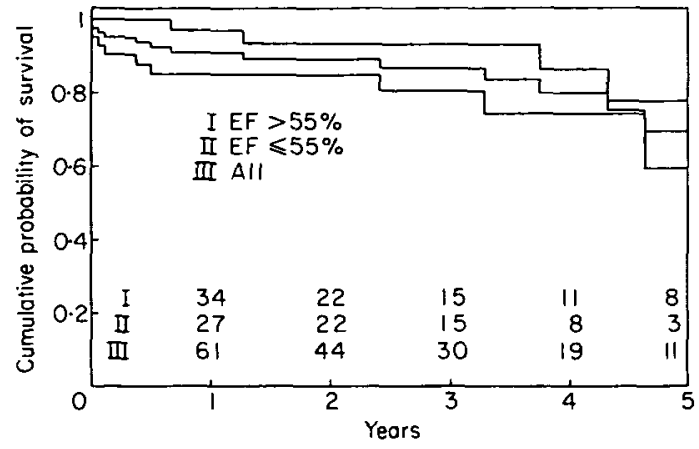

Figure 3 The cumulative probability of survival in 84 patients with prior bypass surgery after attempted PTCA of the vein graft alone, or of the graft and one or more native vessels, was $70 \%$ at 5 years. The left ventricular ejection fraction was a variable adversely affecting long-term survival $(P<0.05)$. The numbers in the lower half indicate the number of patients alive at the end of each year. EF: ejection fraction.

patients required emergency surgery; one of them sustained an acute myocardial infarction.

Fifteen of the 84 patients underwent angioplasty in the setting of a recanalization of a chronic occluded bypass graft. Nine of the 15 procedures were angiographically successful: the angiographic primary success rate was $60 \%$. Five of the 15 patients sustained a proced ure-related myocardial infarction, which was caused by a distal embolization of bypass graft atheroma. Four of the five patients sustained a myocardial infarction shortly after an angiographically successful PTCA (creatine kinase (CK): $684 \mathrm{IU}^{-1}, 280 \mathrm{IU}^{-1}, 800 \mathrm{IU}^{-1}$ and $\left.2900 \mathrm{IU}^{-1}\right)$, and PTCA was not successful in one patient (CK: $\left.1200 \mathrm{IU}^{-1}\right)$.

Of the patients who underwent angioplasty of a nonoccluded graft, two patients sustained a myocardial infarction; one patient after an angiographically successful PTCA (CK unknown) and one patient after a failed PTCA attempt (CK $\left.199 \mathrm{IU}^{-1}\right)$. In both patients the cause of the infarction was an acute occlusion after a dissection in the dilated segment.

The PTCA procedure failed without complications in two cases: in one patient there was failure to cross the stenosis, and in one case, although inflation of the balloon to the maximal pressure limits was achieved, there was insignificant change in the stenosis after angioplasty.

\section{FOLLOW-UP}

The median follow-up period was $2 \cdot 1 \pm 0.4$ years. Thirteen patients died; eight patients died of cardiac events, three patients died of non-cardiac events, and the cause of death was unknown in two patients. Life table analysis (Fig. 3) showed a cumulative probability of survival of $70 \%$ at 5 years. The left ventricular ejection fraction was an important prognostic variable: for patients with a LVEF $\leqslant 55 \%$, the probability of survival was $60 \%$ at 5 years, compared with $78 \%$ for patients with LVEF $>55 \%(P<0.05)$.

After the hospital discharge and during the subsequent follow-up period nine patients sustained a myocardial infarction, and 25 patients underwent bypass surgery. 


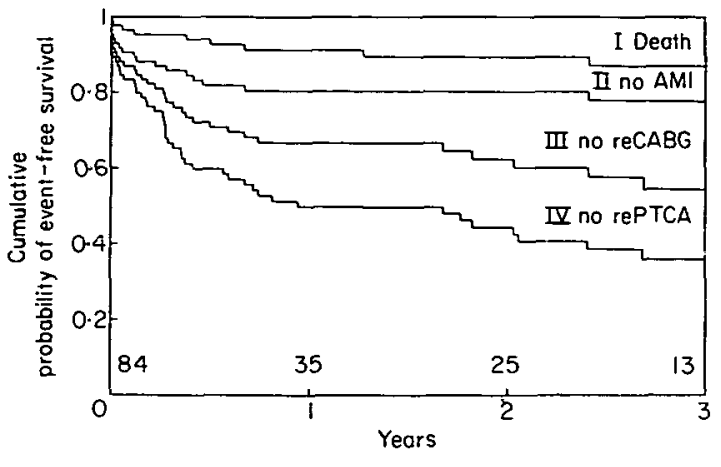

Figure 4 After the median follow-up period of $2 \cdot 1$ years, the cumulative probability of survival without any cardiac event (death, myocardial infarction, repeat bypass surgery, and repeat angioplasty) was $41 \%$ for all 84 patients. The numbers in the lower half indicate the population at risk at the end of each year. reCABG: repeat coronary artery bypass grafting.

Twenty-seven repeat angioplasties were performed; 21 patients underwent one repeat PTCA, five underwent a second repeat PTCA, and one a third repeat PTCA. Of the 59 patients who underwent a first PTCA of the bypass graft alone, 13 patients $(22 \%)$ had graft restenosis. Three of these 13 patients also had progression of the disease in native vessels. One patient did not have restenosis, and underwent a repeat PTCA for disease progression alone. Of the 25 patients who underwent a first PTCA of the graft and one or more native vessels, seven patients ( $28 \%)$ underwent one or more repeat angioplasties. In four patients a repeat PTCA was performed because of restenosis in native vessels, in one patient because of graft restenosis, and in two patients because of restenosis in both the graft and a native vessel. Of the six patients who underwent more than one repeat PTCA, all had graft restenosis for the second or third time. One patient again had graft re-stenosis and also progression of disease in a native vessel.

The event-free survival analysis (survival without infarction, repeat CABG, or repeat PTCA) (Fig. 4) showed that, at the median follow-up of $2 \cdot 1$ years, $41 \%$ of patients were alive and event-free. Of the 69 patients who initially had a successful PTCA $88 \%$ were alive, and $48 \%$ were alive and event-free. At long-term follow-up 25 $(36 \%)$ of the 69 patients had symptomatic improvement of at least one functional angina class or were asymptomatic (Fig. 2). Patients with a relatively short time interval between the previous CABG and PTCA ('graftage') had a better chance of long-term success $(P<0.05)$.

\section{Discussion}

Coronary artery bypass grafting has proved to be a most significant advance in the treatment of obstructive coronary artery disease. Bypass surgery enabled the majority of patients to obtain 5 to 10 years of useful life, with angina pectoris relieved or improved in $80 \%$ to $90 \%$ of them. However, symptoms recur or progress in about $5 \%$ of patients per year ${ }^{[13-16]}$. The main causes of recurrent angina after bypass surgery are: the occurrence of new lesions in vessels not bypassed, new stenoses in the native vessel distal to the anastomosis, and most importantly, the occurrence of new lesions in the bypass graft itself. Approximately $10 \%$ of grafts are occluded within one to two weeks of the operation and $15 \%$ to $20 \%$ by one year ${ }^{[17-23]}$, often because of thrombosis ${ }^{[24]}$ or technical problems involving the distal surgical anastomosis.

Within the first 3 years of bypass surgery, intimal hyperplasia occurs in the body of vein grafts as a diffuse or focal process ${ }^{[23-26]}$. The distal anastomosis appears to be particularly prone to stenosis, although the pathophysiology of this lesion is less well known ${ }^{[23,27]}$. From approximately the fourth year on, vein grafts can become atherosclerotic ${ }^{[24.26-28]}$, and by 5 to 6 years $15 \%$ of grafts will be totally occluded and $52 \%$ will have a luminal narrowing greater than $70 \%{ }^{[21]}$.

In contrast, internal mammary artery grafts have been shown in a number of studies to have markedly superior patency rates in comparison to venous conduits ${ }^{[29.30]}$. Although the problem of bypass graft attrition has been partly met by the increasing use of internal mammary conduits, it is unlikely that their use will solve the problem of re-operation for disease progression. Re-operation is technically more difficult and is generally associated with a higher morbidity and mortality than the first surgical procedure. The incidence of peri-operative acute myocardial infarctions is reported to range between $2.7 \%$ and $10.6 \%$ and mortality rates for coronary re-operations are reported to be between $1.9 \%$ and $8 \%$. Following re-operation $30-40 \%$ of patients may not experience improvement in the their angina ${ }^{[1-6]}$.

Patients who have undergone previous coronary bypass grafting present unique and complex problems if they subsequently require treatment with PTCA. Relative contraindications include: (1) stenosis length greater than balloon length (diffuse disease); (2) friable or ulcerated plaque; (3) risk of cardiogenic shock in the event of acute closure; (4) aorto-iliac disease prohibiting intra-aortic balloon pump placement, if needed; (5) lack of immediate availability of an experienced surgical team ${ }^{[31]}$. Nevertheless, with appropriate patient selection, PTCA can be performed safely and successfully in post CABG patients.

The results of dilatation of saphenous vein grafts have been reported by others to be successful in $75-97 \%$ (Table 2) ${ }^{[7,8,16,31-38]}$. Death, emergency CABG, and myocardial infarction were reported in up to $5 \cdot 3 \%, 4 \cdot 3 \%$ and $6.5 \%$ of patients, respectively. Our results compare favourably with previous reports, although the number of myocardial infarctions is higher in our series. It is likely that this difference is caused by the relatively large number of totally occluded grafts that were attempted. Of the 15 $(18 \%)$ patients who underwent a PTCA of a totally occluded graft, five patients sustained a procedure-related myocardial infarction. Distal embolization of coronary artery bypass graft atheroma, which has been shown to be particularly associated with 'old' grafts ${ }^{[39]}$, was in all cases the cause of these infarctions. The risk of distal embolization during passage with the balloon catheter is probably increased because atherosclerosis in vein grafts tends to 
Table 2 Results of vein graft angioplasty

\begin{tabular}{|c|c|c|c|c|c|c|c|}
\hline First author & $\begin{array}{l}\text { Patients } \\
\text { (n) }\end{array}$ & & & $\begin{array}{c}\text { Primary } \\
\text { success } \\
(\%)\end{array}$ & $\begin{array}{c}\text { Emergency } \\
\text { CABG } \\
(\%)\end{array}$ & $\begin{array}{l}\text { AMI } \\
(\%)\end{array}$ & $\begin{array}{c}\text { Death } \\
(\%)\end{array}$ \\
\hline Douglas $^{[32]}$ & 116 & $\begin{array}{l}\text { SVG, } \\
\text { NV, } \\
\text { IMA, }\end{array}$ & $\begin{array}{r}62 \\
59 \\
1\end{array}$ & $\begin{array}{r}94 \\
83 \\
0\end{array}$ & $2 \cdot 6$ & 1.7 & 0 \\
\hline Block|[34] & 40 & SVG, & 40 & 78 & $2 \cdot 5$ & 0 & NA \\
\hline Dorros $^{[16]}$ & 61 & $\begin{array}{l}\text { SVG, } \\
\text { NV, }\end{array}$ & $\begin{array}{l}33 \\
72\end{array}$ & $\begin{array}{l}79 \\
75\end{array}$ & 1.6 & 4.9 & $3 \cdot 3$ \\
\hline El Gamal[ & 31 & SVG, & 44 & 93 & 0 & $6 \cdot 5$ & 0 \\
\hline Corbelli|i39 & 94 & $\begin{array}{l}\text { SVG, } \\
\text { NV, }\end{array}$ & $\begin{array}{l}47 \\
68\end{array}$ & $\begin{array}{l}92 \\
88\end{array}$ & $4 \cdot 3$ & $2 \cdot 1$ & $1 \cdot 1$ \\
\hline Reeder ${ }^{[36]}$ & 19 & SVG, & 19 & 84 & 0 & $5 \cdot 3$ & $5 \cdot 3$ \\
\hline $\operatorname{Cote}^{[37]}$ & 82 & $\begin{array}{l}\text { SVG, } \\
\text { IMA, }\end{array}$ & $\begin{array}{r}101 \\
5\end{array}$ & $\begin{array}{r}85 \\
100\end{array}$ & $1 \cdot 2$ & $3 \cdot 7$ & 0 \\
\hline $\operatorname{Ernst}^{[7]}$ & 83 & $\begin{array}{l}\text { SVG, } \\
\text { NV, }\end{array}$ & $\begin{array}{l}33 \\
59\end{array}$ & $\begin{array}{l}97 \\
86\end{array}$ & 0 & $2 \cdot 4$ & 0 \\
\hline Pinkerton ${ }^{[3]]}$ & 236 & $\begin{array}{l}\text { SVG, } \\
\text { NV, }\end{array}$ & $\begin{array}{l}100 \\
300\end{array}$ & $\begin{array}{l}93 \\
93\end{array}$ & 3 & NA & $0 \cdot 4$ \\
\hline Cooper ${ }^{[36]}$ & 59 & $\begin{array}{l}\text { SVG, } \\
\text { NV, }\end{array}$ & $\begin{array}{r}24 \\
117\end{array}$ & $\begin{array}{l}75 \\
78\end{array}$ & 0 & $5 \cdot 1$ & $1 \cdot 7$ \\
\hline Present study & 84 & $\begin{array}{l}\text { SVG, } \\
\text { NV, }\end{array}$ & $\begin{array}{l}93 \\
40\end{array}$ & $\begin{array}{l}84 \\
93\end{array}$ & $2 \cdot 4$ & $8 \cdot 3$ & $1 \cdot 2$ \\
\hline
\end{tabular}

IMA: internal mammary artery; NA: not available; NV: native vessel.

involve dilated segments and to be more friable and less fibrocalcific than their counterpart in the native coronary arteries. Therefore, the grafts are particularly vulnerable to disruption and to embolization of relatively large fragments. De Feyter et al. ${ }^{[40]}$ have previously reported our experience with PTCA of totally occluded vein grafts, and have concluded that angioplasty is contraindicated in totally occluded grafts because of a low success rate and an unacceptably high myocardial infarction rate.

After 5 years of follow-up, $70 \%$ of 84 patients were alive. Left ventricular ejection fraction (LVEF) was an important variable in determining long-term survival. In patients with $\mathrm{LVEF} \leqslant 55 \%, 60 \%$ were alive after 5 years, in contrast to $78 \%$ of the patients with LVEF $>55 \%$ $(P<0.05)$. Of the patients who had had a successful PTCA $48 \%$ were alive and event-free after the median follow-up of $2 \cdot 1$ years, and symptomatic improvement or no symptoms at all occurred in $36 \%$ of patients (Fig. 2). Patients with a relatively short time interval between the recurrence of angina after bypass grafting and the PTCA attempt ('graftage') had better long-term results $(P<0.05)$.

\section{Conclusions}

Our results indicate that PTCA of saphenous vein grafts may be an alternative to re-operation in some patients with previous bypass surgery, particularly those in whom surgery is not a reasonable alternative. However, in patients with a short time interval between bypass surgery and angioplasty better long-term results may be achieved. Angioplasty is contraindicated in totally occluded vein grafts, because of an unacceptable complication rate.
We thank Ron van Domburg of the Computer Group of the Thoraxcenter for his great help in data processing.

\section{References}

[1] Reul GJ, Cooley DA, Ott DA, Coelho A, Chapa L, Eterovic I. Reoperation for recurrent coronary artery disease. Arch Surg 1979; 14: 1269-75.

[2] Vouhe P, Grondin CM. Reoperation for coronary graft failure: clinical and angiographic results in 43 patients. Ann Thorac Surg 1979; 328-34.

[3] Loop FD, Cosgrove DM, Kramer JR et al. Late clinical and arteriographic results in 500 coronary artery reoperations. J Thorac Cardiovasc Surg 1981; 675-85.

[4] Krause AH, Page US, Bigelow JC, Okies JE, Dunlap SF. Reoperation in symptomatic patients after direct coronary artery revascularization. J Thorac Cardiovasc Surg 1978; 75: 499-504.

[5] Lytle BW, Loop FD, Cosgrove DM et al. Fifteen hundred coronary reoperations: results and determinants of early and late survival. J Am Coll Cardiol 1986; 7: 31 A (Abstr)

[6] Laird-Meeter K, van Domburg R, van den Brand M, Lubsen J, Bos E, Hugenholtz PG. Incidence, risk and outcome of reintervention after aortocoronary bypass surgery. Br Heart J 1987; 57: 427-35.

[7] Ernst SM, van der Feltz TA, Ascoop CA et al. Percutaneous transluminal coronary angioplasty in patients with prior coronary artery bypass grafting: long-term results. J Thorac Cardiovasc Surg 1987; 93: 268-75.

[8] Dorros G, Lewin RF, Mathiak LM et al. Percutaneous transluminal coronary angioplasty in patients with two or more previous coronary artery bypass grafting operations. Am J Cardiol 1988; 61: 1243-7.

[9] Suryapranata H, Serruys PW, Vermeer F et al. Value of immediate coronary angioplasty following intracoronary thrombolysis in acute myocardial infarction. Cathet Cardiovasc Diagn 1987; 13: 223-32.

[10] de Feyter PJ, van den Brand M, Serruys PW. Increase of initial success and safety of single-vessel percutaneous transluminal coronary angioplasty in 1371 patients: a seven-year experience. J Intervent Card 1988; 1: 3-9. 
[11] Serruys PW, de Feyter PJ, van den Brand M, Luijten HE, Hugenholtz PG. How to bypass surgery when you already have a bypass on a bypass? (Dutch publication) Ned Tijdschr Geneeskd 1986; 4: 2089-91.

[12] Pop G, van den Brand M, Essed N, de Feyter PJ, Suryapranata H, Serruys PW. Bypass graft occlusion: repeat bypass surgery or dilatation of the graft? (Dutch publication) Hart Bulletin 1987; 18: 123-6.

[13] Laird-Meeter K, ten Katen HJ, Brower RW et al. Angina pectoris, 1 to 10 years after aorto-coronary bypass surgery. Eur Heart J 1983; 5: 35-42.

[14] Brower R, Laird-Meeter K, Serruys P, Meester G, Hugenholtz PG. Long-term follow-up after coronary artery bypass graft surgery: progression and regression of disease in native coronary circulation and bypass grafts. Br Heart J 1983; 50:42-7.

[15] Campeau L, Lesperance J, Hermann J, Corbara F, Grondin $\mathrm{CM}$, Bourassa MG. Loss of improvement of angina between 1 and 7 years after aortocoronary bypass surgery: correlations with changes in vein grafts and in coronary arteries. Circulation 1979; 60: I1-5.

[16] Dorros G, Johnson WD, Tector AJ, Schmahl TM, Kalush SL, Janke L. Percutaneous transluminal coronary angioplasty in patients with prior coronary artery bypass grafting. J Thorac Cardiovasc Surg 1984; 87: 17-26.

[17] Fitzgibbon GM, Burton JR, Leach AJ. Coronary bypass graft fate: angiographic grading of 1400 consecutive grafts early after operation and of 1132 after one year. Circulation 1978; 57: $1070-4$.

[18] Lawrie GM, Lie JT, Morris GC Jr, Beazley HL. Vein graft patency and intimal proliferation after aortocoronary bypass: early and long-term angiopathologic correlations. Am J Cardiol 1976; 38: 856-62.

[19] Marco JD, Barner HB, Kaiser GC, Codd JE, Mudd JG, Willman V. Operative flow measurements and coronary bypass graft patency. J Thorac Cardiovasc Surg 1976; 71: 545-7.

[20] Pantely GA, Goodnight SH, Rahimtoola SH et al. Failure of antiplatelet and anticoagulant therapy to improve patency of grafts after coronary artery bypass: a controlled, randomized study. N Engl J Med 1979; 301: 962-6.

[21] Brown BG, Cukignan RA, DeRouen T et al. Improved graft patency in patients treated with platelet-inhibiting therapy after coronary bypass surgery. Circulation 1985; 72: 138-46.

[22] Bourassa MG, Campeau L, Lesperance J, Grondin CM. Changes in grafts and in coronary arteries after saphenous vein aortocoronary bypass surgery. In: Hammermeister KE, eds. Coronary bypass surgery; the late results, New York; Praeger Publisher, 1983, 293-310.

[23] Bulkley BH, Hutchins GM. Accelerated "atherosclerosis": a morphologic study of 97 saphenous vein coronary artery bypass grafts. Circulation 1977; 55: 163-9.

[24] Lie JT, Lawrie GM, Morris GC. Aortocoronary bypass saphenous vein graft atherosclerosis. Am J Cardiol 1977; 40: 906-14.
[25] Spray TL, Roberts WC. Changes in saphenous veins used as aortocoronary bypass grafts. Am Heart J 1977; 94: 500-16.

[26] Smith SH, Geer JC. Morphology of saphenous vein coronary artery bypass grafts. Arch Pathol Lab Med 1983; 107: 13-8.

[27] Griffith LSC, Bulkley BH, Hutchins GM, Brawley RK. Occlusive changes at the coronary artery-bypass graft anastomosis: morphologic study of 95 grafts. J Thorac Cardiovasc Surg 1977; 73: 668-79.

[28] Neitzel GF, Barboriak JJ, Pintar K, Qureshi I. Atherosclerosis in aortocoronary bypass grafts: morphologic study and risk factor analysis 6 to 12 years after surgery. Arteriosclerosis 1986; 6: 594-600.

[29] Loop FD, Lytle BW, Cosgrove DM et al. Influence of the internal-mammary-artery graft on 10-year survival and other cardiac events. N Engl J Med 1986; $314: 1-6$

[30] Cameron A, Kemp HG, Green GE. Bypass surgery with the internal mammary graft: 15 year follow-up. Circulation 1986; 74 (Suppl III): 30-6.

[31] Pinkerton CA, Slack JD, Orr CM, Vantassel JW, Smith ML. Percutaneous transluminal angioplasty in patients with prior myocardial revascularization surgery. Am J Cardiol 1988; 61 : $15 \mathrm{G}-22$.

[32] Douglas JS, Gruentzig AR, King SB et al. Percutaneous transluminal angioplasty in patients with prior coronary artery bypass surgery. J Am Coll Cardiol 1983; 745-54.

[33] El Gamal M, Bonnier H, Michels R, Heijman J, Stassen E. Percutaneous transluminal angioplasty of stenosed aortocoronary bypass grafts. Br Heart J 1984; 52: 617-20.

[34] Block PC, Cowley MJ, Kaltenbach M, Kent KM, Simpson J. Percutaneous angioplasty of stenoses of bypass grafts or of bypass graft anastomotic sites. Am J Cardiol 1984; 53:666-8.

[35] Corbelli J, Franco I, Hollman J, Simpfendorfer C, Galan K. Percutaneous transluminal coronary angioplasty after previous coronary artery bypass surgery. Am J Cardiol 1985; 56 : 398-403.

[36] Reeder GS, Bresnahan JF, Holmes DR et al. Angioplasty for aortocoronary bypass graft stenosis. Mayo Clin Proc 1986; 61 : 14-9.

[37] Cote G, Myler RK, Stertzer SH et al. Percutaneous transluminal angioplasty of stenotic coronary artery bypass grafts: 5 years' experience. J Am Coll Cardiol 1987; 9: 8-17.

[38] Cooper I, Ineson N, Demirtas E et al. Role of angioplasty in patients with previous coronary artery bypass surgery. Cathet Cardiovasc Diagn 1989; 16: 81-6.

[39] Aueron F, Gruentzig AR. Distal embolization of a coronary bypass graft atheroma during percutaneous transluminal coronary angioplasty. Am J Cardiol 1984; 53:953-4.

[40] de Feyter PJ, Serruys P, van den Brand M, Meester H, Beatt K, Suryapranata $\mathrm{H}$. Percutaneous transluminal angioplasty of a totally occluded venous bypass graft: a challenge that should be resisted. Am J Cardiol 1989; 64: 88-9. 